\title{
Influence of urban form on the cooling effect of a small urban river
}

Park, Chae Yeon; Lee, Dong Kun; Asawa, Takashi; Murakami, Akinobu; Kim, Ho Gul; Lee, Myung-Kyoon; Lee, Ho Sang

Published in:

Landscape and Urban Planning

Link to article, DOI:

10.1016/j.landurbplan.2018.10.022

Publication date:

2019

Document Version

Peer reviewed version

Link back to DTU Orbit

Citation (APA):

Park, C. Y., Lee, D. K., Asawa, T., Murakami, A., Kim, H. G., Lee, M-K., \& Lee, H. S. (2019). Influence of urban form on the cooling effect of a small urban river. Landscape and Urban Planning, 183, 26-35.

https://doi.org/10.1016/j.landurbplan.2018.10.022

\section{General rights}

Copyright and moral rights for the publications made accessible in the public portal are retained by the authors and/or other copyright owners and it is a condition of accessing publications that users recognise and abide by the legal requirements associated with these rights.

- Users may download and print one copy of any publication from the public portal for the purpose of private study or research.

- You may not further distribute the material or use it for any profit-making activity or commercial gain

- You may freely distribute the URL identifying the publication in the public portal 
Influence of urban form on the cooling effect of a small urban river

Abstract: Urban warming due to increased urbanization is becoming a serious environmental problem, requiring urban planners to consider heat mitigation strategies that reduce urban air temperature. Urban rivers play an important role in reducing urban heat through evaporation and transfer of sensible heat, known as the river cooling effect (RCE). We used detailed field measurements to calculate the river cooling intensity (RCI) and river cooling distance (RCD) for the Cheonggye River in Seoul, Korea in order to determine the relationship between RCE and urban form at different times of day during summer. Our results showed that the Cheonggye River had a mean RCI of $0.46^{\circ} \mathrm{C}$ and a mean RCD of $32.7 \mathrm{~m}$ at 2 p.m. and a mean RCI of $0.37^{\circ} \mathrm{C}$ and a mean RCD of $37.2 \mathrm{~m}$ at 10 p.m. Spatial variations in RCE were negatively correlated with street width and mean building height at 2 p.m., indicating that narrower streets and lower buildings would improve the RCE. In addition, temporal variations in RCE were related to changes wind speed at similar humidity levels. Our results show that the urban form surrounding a river can affect the local RCE, suggesting that landscape and urban planners should consider urban form as a variable affecting urban heat and RCE.

Keywords: urban warming; mobile survey; cooling effect; street width; building height; wind speed

\section{Introduction}

2 Urban areas can experience intense warming events with temperatures increasing more 
3 rapidly than in surrounding rural areas (Sugawara et al., 2015). Processes contributing to such

4 urban warming include absorption of solar radiation by paved surfaces, heat reflection from

5 high-rise buildings, and anthropogenic heat release (Mochida \& Lun, 2008). Urban warming

6 has negative effects on both humans and the natural environment that are expected to increase

7 in the future (Imhoff, Zhang, Wolfe, \& Bounoua, 2010; Lin, Yu, Chang, Wu, \& Zhang, 2015;

8 O'Loughlin et al., 2012). Therefore, urban heat mitigation strategies should be developed at

9 the urban planning stage. Effective heat mitigation strategies include reducing solar radiation

10 absorption through shading, increasing the albedo of urban elements, and encouraging

11 evaporative cooling by expanding green or water surfaces (Rizwan, Dennis, \& Liu, 2008;

12 Vidrih \& Medved, 2013).

13 Water bodies are recognized as cooling islands in urban areas (Chang, Li, \& Chang, 2007;

14 Coutts, Tapper, Beringer, Loughnan, \& Demuzere, 2012; Du et al., 2016); urban rivers in

15 particular have clear heat mitigation and cooling effects (Du et al., 2016). The river cooling

16 effect (RCE) occurs in two ways: by generating latent heat via evaporation and by

17 transferring sensible heat between the river's surface and the urban air (Webb \& Zhang, 1997). Moreover, rivers generate an effective cooling zone by diffusing cool air throughout nearby areas (Kim, Cha, \& Jung, 2014; Saaroni \& Ziv, 2003). Fig. 1 shows the cooling effect zone of an urban river, where the cooling effect is defined by its intensity and distance (Du et al., 2016; Honjo \& Takakura, 1990; Jaganmohan, Knapp, Buchmann, \& Schwarz, 2016). 


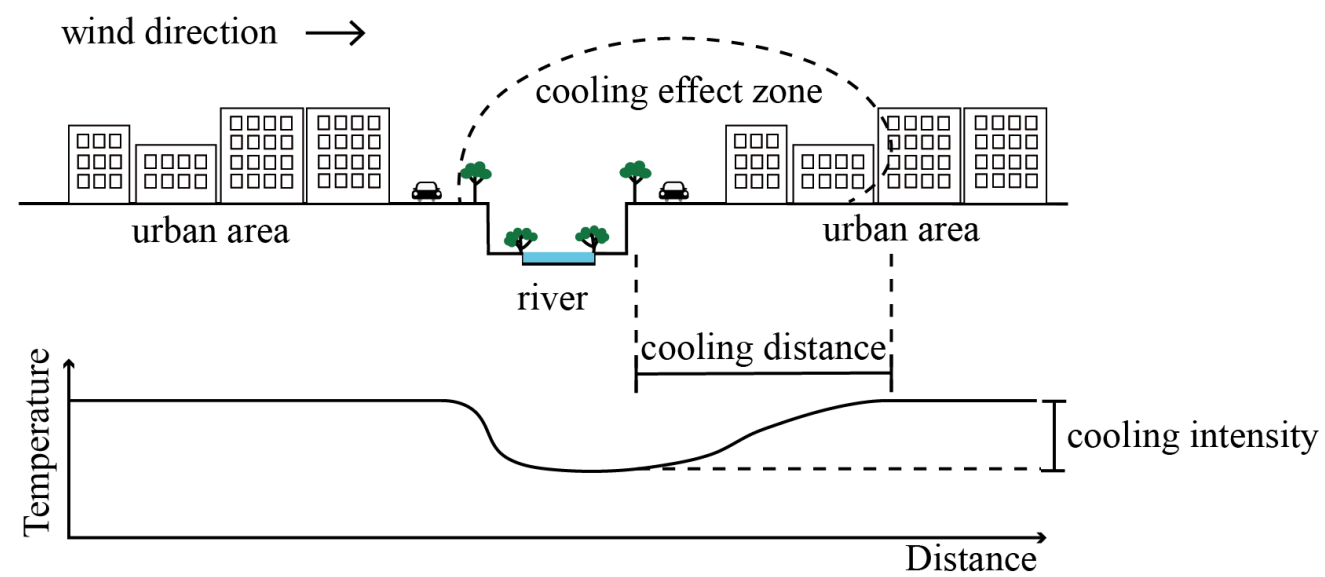

Fig. 1. Conceptual diagram of the urban river cooling effect (RCE) (image reproduced from Honjo \& Takakura, 1990).

RCE varies with river characteristics such as geometry and shape index (Du et al., 2016; Sun, Chen, Chen, \& Lü, 2012), vegetation cover and river bank height (Du et al., 2016; Murakawa, Sekine, Narita, \& Nishina, 1991), and climatic factors. Wind speed is a particularly important factor determining the cooling effect zone (Katayama, Hayashi, Shiotsuki, \& Kitayama, 1990; Tominaga, Sato, \& Sadohara, 2015), while air or land temperature and humidity are also influential (Du et al., 2016; Edinger, Dutterweiler, \& Geyer, 1968; Webb \& Zhang, 1997).

However, the studies cited above did not consider urban characteristics despite their focus on urban areas. Each urban area has a specific infrastructure layout, or form, that alters the microclimate in the urban canopy layer (UCL) lying between the ground and the boundary layer (Lee, 2011; Mills, 1997). Urban form can affect radiation transfer or airflow dispersal in the UCL, driving variations in RCE within the surrounding area (Lin et al., 2015).

Despite the importance of urban form, only a few studies have analyzed its impact on the RCE. Murakawa et al. (1991) compared three streets near a river in Japan to determine the 
impact of building density and street width on RCE, finding that the RCE increased as building density decreased or streets became narrower. Hathway \& Sharples (2012) compared open and closed street forms along a river in the U.K., revealing that open streets experienced a greater cooling effect from the river. Manteghi, Lamit, \& Ossen (2015) determined that building orientation also influences RCE. However, more studies on the relationship between urban form and RCE are required to better guide the design of urban areas with respect to developing and maintaining an effective RCE.

One aspect of this process involves determining the horizontal temperature gradient from the river to the nearby urban area. Some researchers have studied the cooling effect using land surface temperature as acquired from remote sensing (Chen, Tan, Wei, \& Su, 2014; Du et al., 2016; Sun et al., 2012). However, these studies were limited to a regional scale and only dealt with large rivers, whereas urban rivers are typically small. Although some previous studies have attempted to analyze the effect of small rivers using field measurements to acquire screen level temperature data, their measurements were too sparsely distributed to accurately measure the cooling distance (Hathway \& Sharples, 2012; Kim et al., 2014). Accurate RCE research requires data with high spatial resolution.

In order to fill these gaps in previous research, in this study we considered the effect of urban form on the RCE of a small urban river under summer conditions. We defined the urban form using street width and building height along with high-resolution temperature data with a temporal range of 4 days. Our main research questions were:

1) What is the most effective field measurement method for analyzing RCE?

2) What are the quantitative effects of each urban form characteristic on RCE?

3) How and why does the impact of urban form on RCE vary temporally? 
63 Our results have two main applications: 1) to better inform future studies of RCE,

64 particularly field measurements of high-resolution air temperature and 2) to improve design

65 guidelines for urban rivers and nearby areas in order to mitigate urban warming and

66 improve thermal comfort.

67

68

\section{Materials and Methods}

69

2.1. Study overview

70 This study was composed of three steps: field measurements, RCE calculations, and 71 statistical analysis. For the field measurements, we used a mobile survey to increase the 72 number of measurement points. We subsequently calculated RCE, including the river cooling 73 intensity (RCI) and the river cooling distance (RCD), using air temperature gradients and 74 their trend lines. Finally, we performed a correlation analysis to determine the effects of 75 urban form on RCE and to examine the causes of RCE variations. A complete flow chart of our methodology is presented in Fig. 2. 


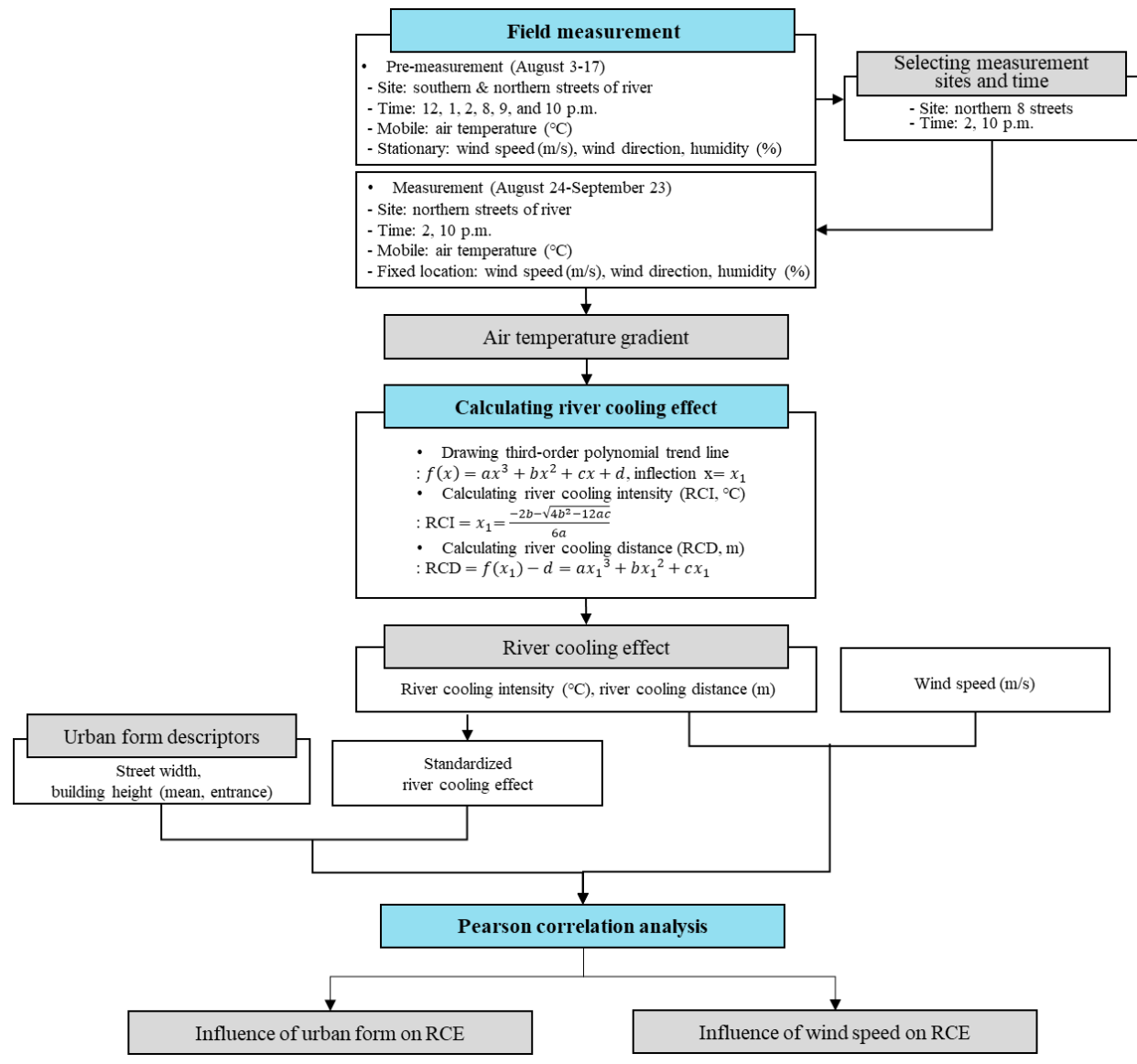

Fig. 2. Flow chart showing the analysis procedures used in this study.

We focused on the Cheonggye River, a small urban waterway located in the center of Seoul, South Korea. This area has a hot and humid summer lasting from June to September, with heat waves common in August. As frequent rains are common until July, sunny days in August and September were selected for field measurements. The study site was occupied by a highway until 2003, but the Cheonggye River was artificially restored over the next two

87 years, now flowing from west to east across the central region of Seoul for $5.8 \mathrm{~km}$ (Kim et al., 2008). The main study site was located in an upstream (western) portion of the river where eight streets were selected for analysis, each approximately $200 \mathrm{~m}$ in length (Fig. 3). 


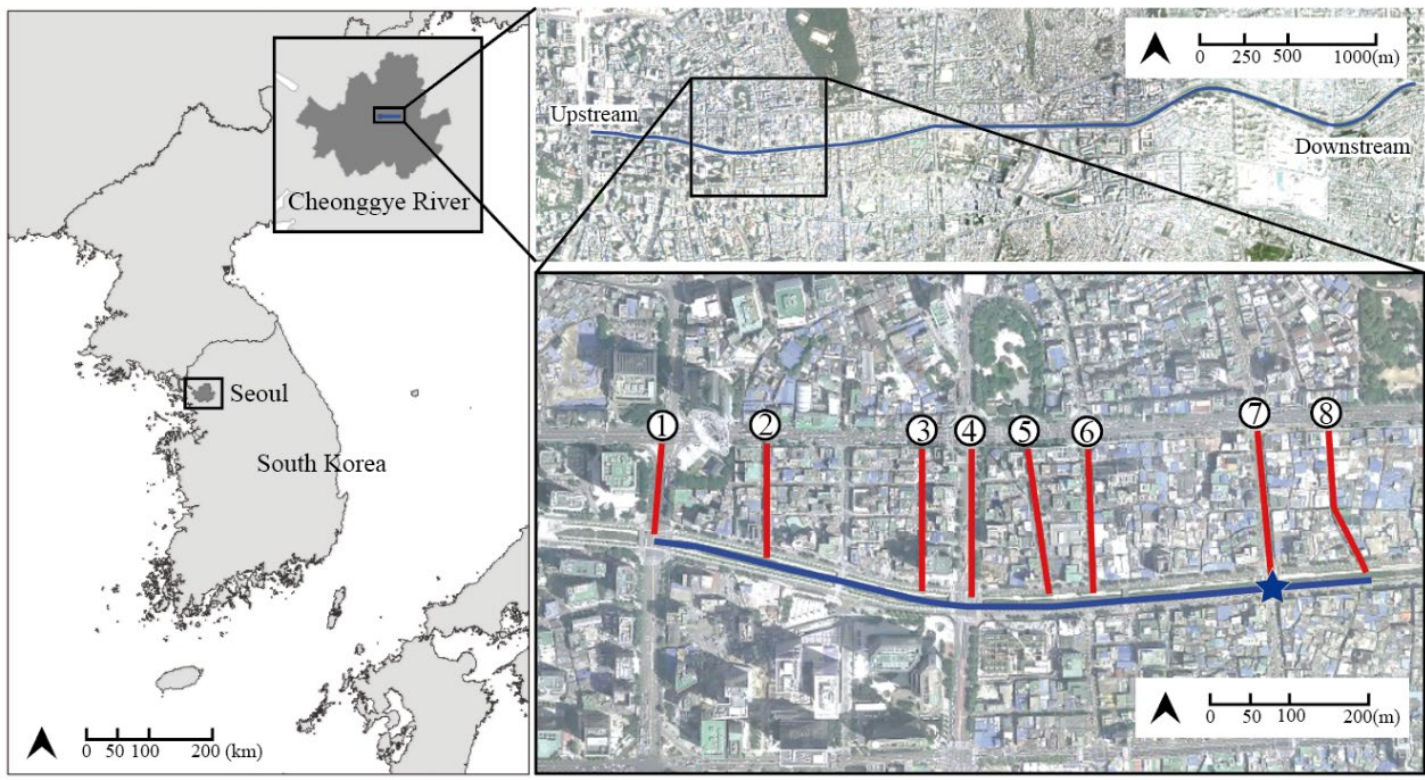

Fig. 3. Monitoring sites on the Cheonggye River (blue line). Red lines indicate the tracks of eight mobile street surveys; the blue star marks a fixed-location weather station.

We conducted pre-measurement analysis from August $3-17^{\text {th }}$ to determine the optimum study conditions. The dominant wind direction, which has a major influence on the formation of the cooling effect zone (Fig. 1), was WSW, meaning that the RCE would be more effective on the north bank than the south bank of the river. Furthermore, metro station entrances were located at the end of southern streets near the river, which could affect air temperature measurements. Therefore, we selected eight streets on the north bank of the Cheonggye River.

We further selected 2 p.m. and 10 p.m. as representative time slots for evaluating RCE during day and night because the former was the hottest time of the day with the biggest difference between river surface temperature and urban air temperature while the latter had the most stable weather of the day with minimal artificial impacts (such as traffic). Four days were selected to represent an average RCE; these were all clear and cloudless, except for one day and one night, and humidity was almost constant so that the influence of humidity on 
RCE could be controlled. The average air temperature, based on measurements from the nearest Automatic Weather Station (AWS), was $27.7^{\circ} \mathrm{C}$ at 2 p.m. and $23.8^{\circ} \mathrm{C}$ at 10 p.m. (Table 1).

The land use pattern in the study area was uniformly commercial although the urban form varied in terms of street width and building height. The basic structure consisted of an urban canyon formed by building walls and streets (Nunez \& Oke, 1977) (Fig. 4), in which the main factors influencing specific urban thermal conditions are street width, building height, and building orientation (Abreu-Harbich, Labaki, \& Matzarakis, 2014). In this study, building orientations in all eight streets were the same, so only street width and building height were used for analysis. Street width (SW) was defined as the distance between buildings on each side of the street, which remained constant within each street. However, as building height varied within a street, we used two building height descriptors: mean building height (MH) and frontage building height ( $\mathrm{FH}$, that of buildings facing the river). The latter is an important descriptor because high-rise buildings facing the river can prevent the outwards spread of cool air (Jamei, Rajagopalan, Seyedmahmoudian, \& Jamei, 2016). These parameters were calculated as:

$$
\begin{gathered}
\mathrm{MH}=\sum_{j=1}^{n}\left(\frac{w_{j}}{\sum_{i=1}^{n} w_{i}} h_{j}\right) \\
\mathrm{FH}=\frac{h 1+h 2}{2}
\end{gathered}
$$

where $w$ is the width of each building, $h$ is height of each building, and $h 1$ and $h 2$ are the height of buildings facing the river. $\mathrm{MH}$ is weighted based on building width and $\mathrm{FH}$ is the average height of the two buildings facing the river (on either side of the street). Building height and street width data were obtained from the Integrated Real Estate Information 
dataset (Ministry of Land, Infrastructure and Transport of Korea) and the Korea National Spatial Data Infrastructure Portal, respectively. SW varied from 6-42 m, MH varied from 7.4-49.1 m, and FH varied from 14.5-69 m (Table 2).

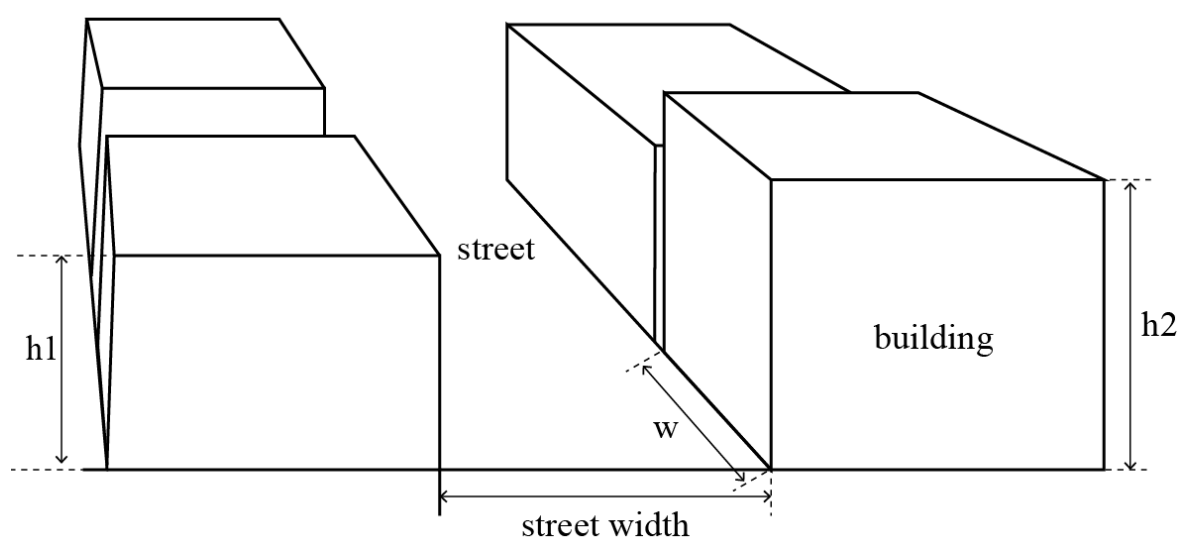

Fig. 4. Schematic depiction of an urban canyon (image reproduced from Nunez \& Oke, 1997).

(1)

(1)

\subsection{Field measurements}

Urban microclimates are so complex that a fixed weather station cannot provide sufficient spatial resolution (Rajkovich \& Larsen, 2016; Sugawara et al., 2015). Thus, we used mobile surveys for field measurements, which provide higher spatial resolution data at a lower cost than a fixed weather station (Stewart, 2011) and have additional advantages for measuring urban microclimates; catching micro heat wave, covering large study sites, measuring in narrow spaces (Brandsma \& Wolters, 2012; Coseo \& Larsen, 2014). When studying urban microclimates, air temperature should be measured at a screen level (1-2 m above ground) of the UCL (Oke, 2004; Stewart \& Oke, 2012; Stewart, 2011). This presents some difficulties, 
147 however, in that the thermometer can receive radiation from outdoor materials and the air

148 flow can be stagnant because of many obstacles. To overcome these difficulties, radiation 149 shielding and ventilation are recommended for the thermometer (Oke, 2004). In this study, a

150 T-type thermocouple was shielded by an aluminum double cylinder and a battery operated 151 ventilator was mounted on the bottom of a cylinder (He \& Hoyano, 2010; Jaganmohan et al., 152 2016). This thermocouple used a $0.127 \mathrm{~mm}$ diameter sensor that was sensitive to outdoor air 153 and was connected to a data logger (Oneset Computer Corporation, USA) that recorded the 154 air temperature in $1 \mathrm{sec}$ intervals with an accuracy of $\pm 0.6^{\circ} \mathrm{C}$ and a resolution of $0.02{ }^{\circ} \mathrm{C}$ 155 (Fig. 5a).

156 Two people walked the streets at the same speed (about $1.4 \mathrm{~m} / \mathrm{s}$ ). Each walked four streets 157 for 30 minutes, with two thermometers mounted on their shoulders $1.5 \mathrm{~m}$ above the ground. 158 The thermometers were verified against each other every day prior to measurement. Survey 159 tracks were measured twice, at 2 p.m. and 10 p.m. Each point on the survey track therefore 160 had four air temperature data points, which were then averaged. A fixed-location weather station (Vantage Pro 2, Davis Instruments, USA) was mounted on a nearby bridge; this took measurements every 5 minutes of humidity ( $\pm 3 \%$ accuracy) and wind speed $( \pm 0.4 \mathrm{~m} / \mathrm{s}$ accuracy) (Fig. 5b). The humidity and wind speed values were averaged per hour. 
(a)

165

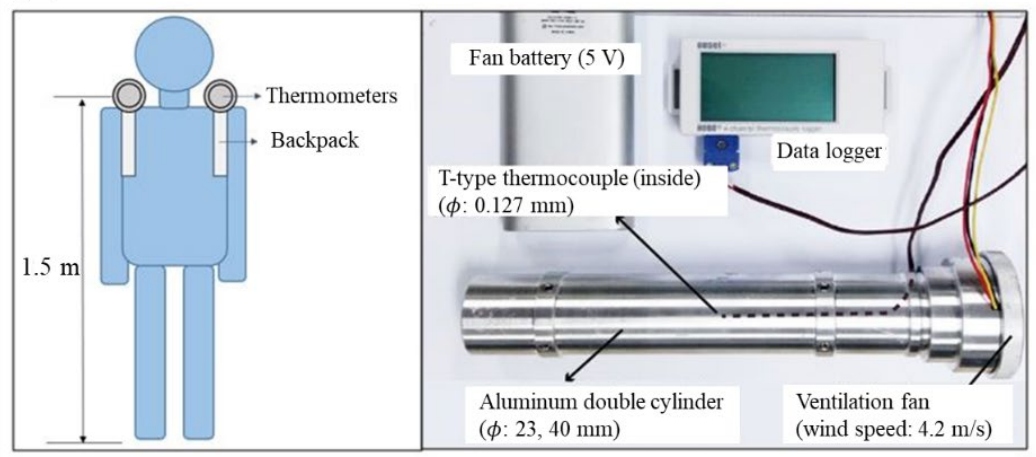

(b)

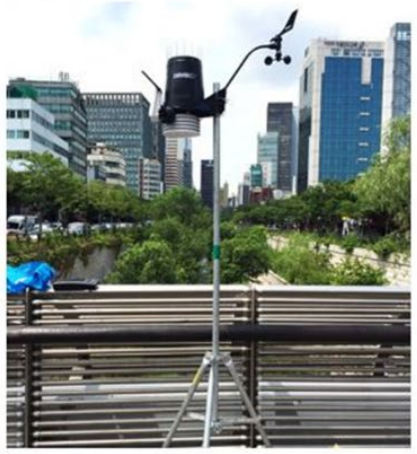

\subsection{Calculating RCE}

We calculated RCE using a third-order polynomial method developed by Lin et al. (2015) after noting that the further an area was from a river, the smaller the cooling effect was.

Cooling intensity is defined as the difference in air temperature between a river and an urban area (Feyisa, Dons, \& Meilby, 2014) and the cooling distance is the distance from a river to the point in the temperature curve where temperature abruptly changes or flattens out (Sun et al., 2012), as shown in Fig. 6. Over this distance, air temperature increases until an inflection point and then decreases due to another thermal influence from buildings, cars, and roads.

The trend line of this phenomena fits a third-order polynomial, $\mathrm{f}(\mathrm{x})$, in which the $\mathrm{x}$-axis denotes the distance from the river while the y-axis denotes the air temperature. If we set the inflection x-value as $x_{1}$, then RCD is $x_{1}$ and RCI is $f\left(x_{1}\right)-d$, as shown in the third-order polynomial equations first proposed by Chen et al. (2012) and developed by Jaganmohan et al. (2016):

$$
\mathrm{RCD}=x_{1}=\frac{-2 b-\sqrt{4 b^{2}-12 a c}}{6 a}
$$




$$
\mathrm{RCI}=f\left(x_{1}\right)-d=a x_{1}^{3}+b x_{1}^{2}+c x_{1}
$$

184 When the air temperature data do not fit a third-order polynomial (negative polynomial or 185 flat), the values of RCI and RCD are zero. Based on the results of previous studies, we restricted the maximum RCD to $100 \mathrm{~m}$ to reduce other cooling influences (except for two instances: street5 at 2 p.m. and 10 p.m. on August $\left.30^{\text {th }}\right)$.

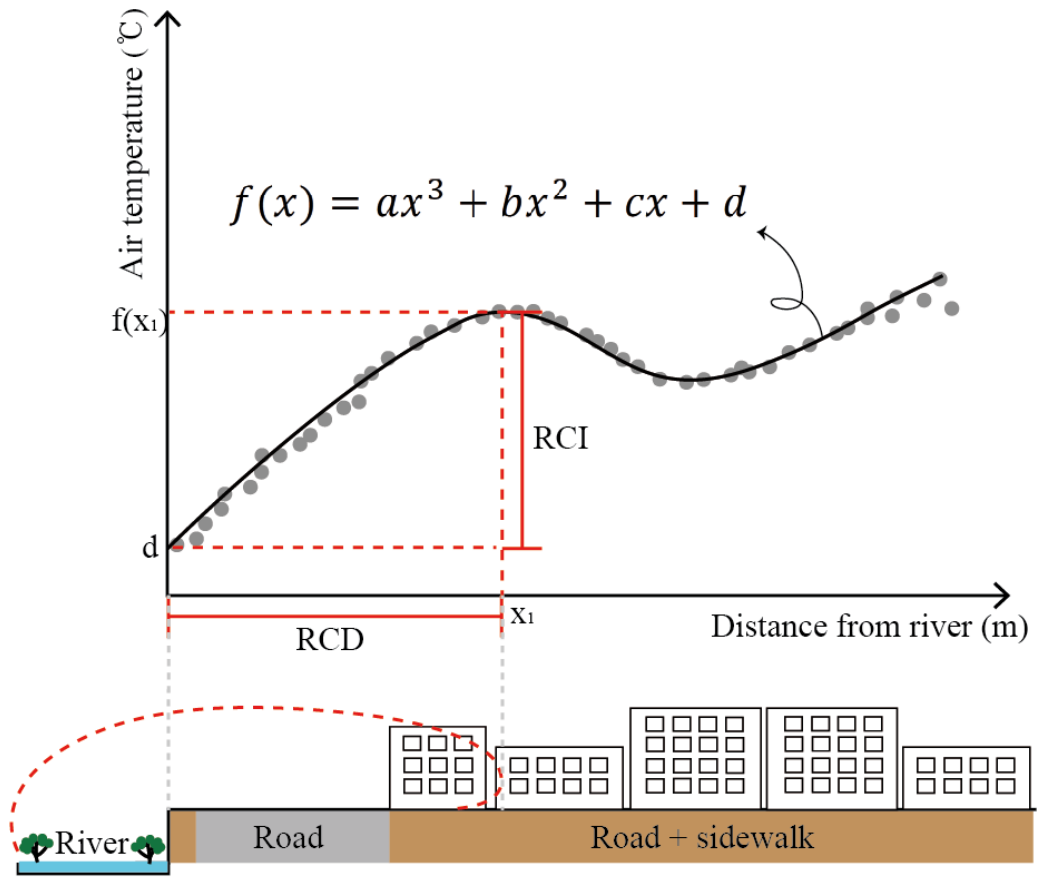

Fig. 6. Schematic diagram of river cooling intensity (RCI) and river cooling distance (RCD).

\subsection{Statistical analysis}

To examine the influence of urban form, we used SPSS statistics software (IBM, USA) to conduct Pearson correlation analysis with the RCI and RCD data from all four days and eight streets $(n=32)$ along with the $\mathrm{SW}, \mathrm{MH}$, and $\mathrm{FH}$ values along all eight streets. As the RCE can vary with measurement date because of climate factors such as humidity and wind speed, we standardized RCE for each day before performing the correlation analysis in order to 
compare values from different dates. However, to examine the influence of climate on RCE and determine the temporal variations due to wind speed, we used non-standardized RCE for the relevant analysis.

\section{Results}

\subsection{Air temperature gradient}

The horizontal air temperature gradient results showed two trends. For example, Fig. 7 shows the air temperature gradient at 2 p.m. on August $24^{\text {th }}$. Six streets $(2,3,5,6,7$, and 8$)$ had explicit polynomial functions with third-order polynomial trend lines, indicating a clear RCE where air temperature gradually increased with distance from the river, following the exponential curve until the inflection point (Murakawa et al., 1991). Two streets (1 and 4) had flat or implicit functions, indicating zero RCE; thus RCE could not be determined. These streets' width and building height were longer than the others' and included a vehicular bridge over the river, resulting in high traffic and no RCE. The distance to the inflection point varied, along with the difference in air temperature between the river and the inflection point, indicating that RCD and RCI varied from street to street. 
(a) Explicit function
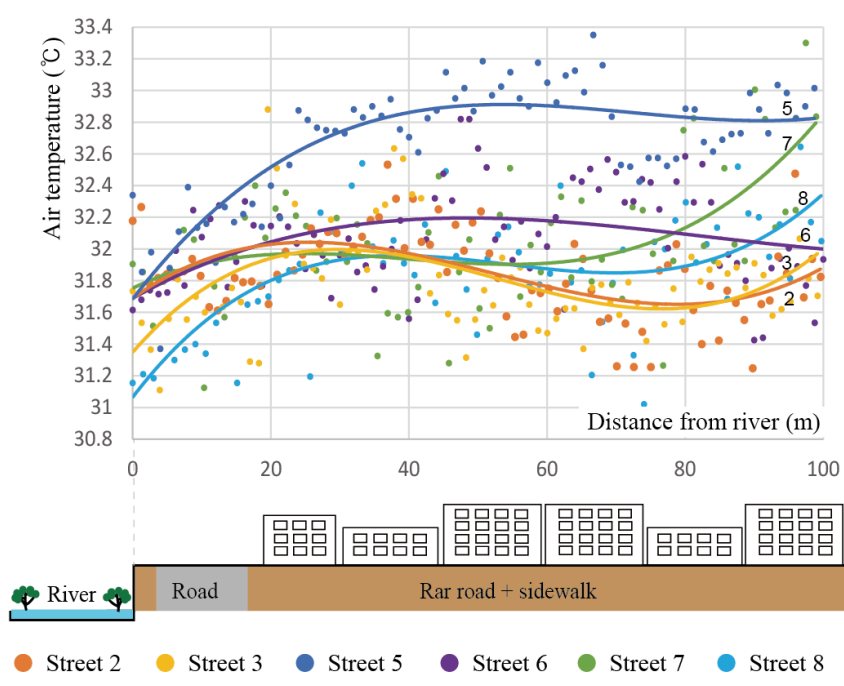

(b) Implicit function

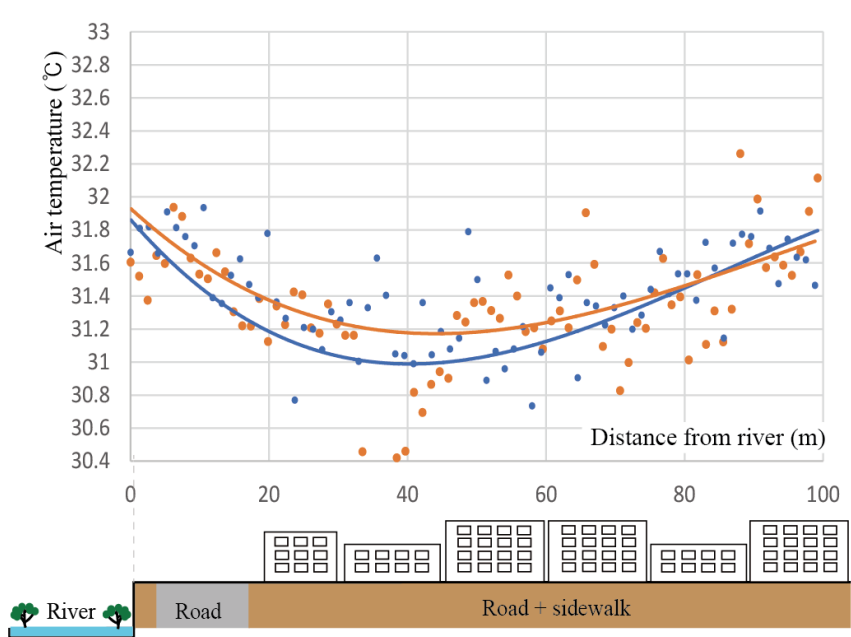

216 Fig. 7. Horizontal air temperature gradients at 2 p.m. on August $24^{\text {th }}$, 2016. (a) Explicit 217 function: air temperature initially increases with distance from the river and streets show 218 positive RCE values. (b) Implicit function: air temperature initially decreases with distance 219 from the river and streets show zero RCE. 
(a) 2 p.m.

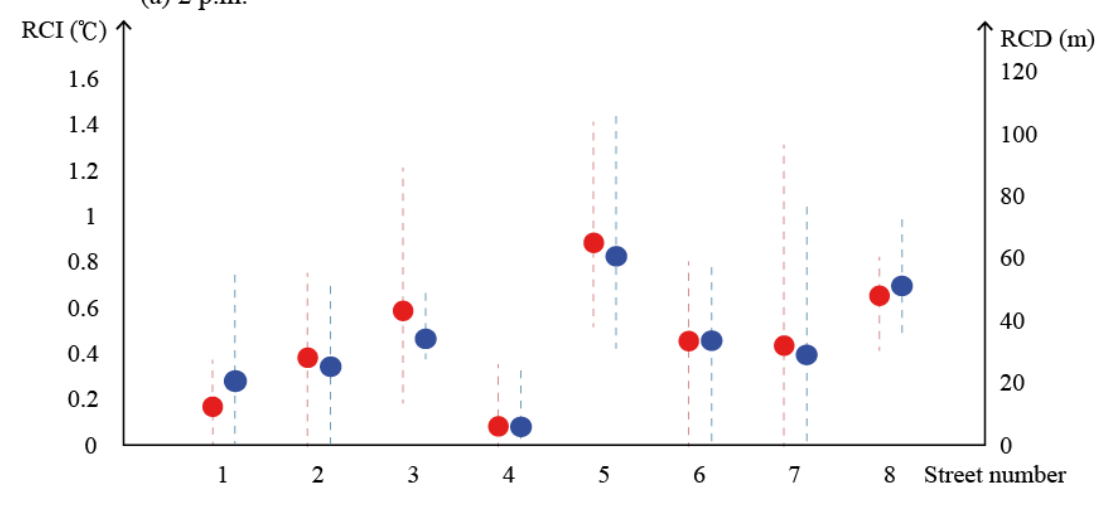

(b) 10 p.m

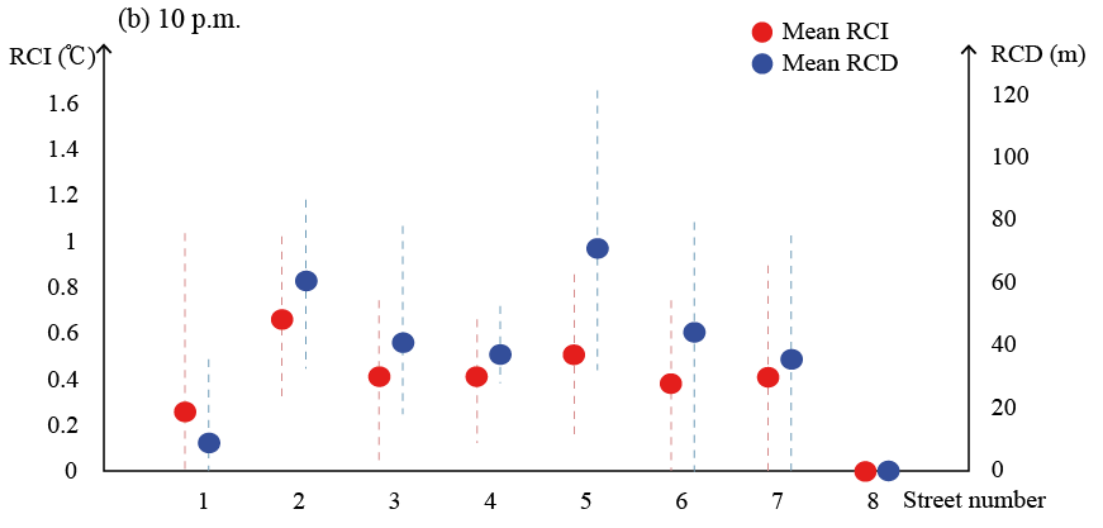

Fig. 8. RCI and RCD for each street calculated at (a) 2 p.m. and (b) 10 p.m. Dotted lines show the range of values.

234 with standardized RCE at 2 p.m. (Table 3). The correlation coefficients between SW and

235 standardized RCI and RCD indicated a lower cooling effect in wide streets. The correlation coefficients between $\mathrm{MH}$ and standardized RCI and RCD indicated that high-rise buildings 
restricted the cooling effect on the streets. However, FH and RCE showed no correlation, suggesting that the height of buildings facing the river was not important for the RCE. As shown in Fig. 9, the median RCE decreased as SW and MH increased but with large interquartile ranges, indicating a relatively large range in standardized RCD and RCI depending on measurement date. However, at 10 p.m., standardized RCE and urban form showed no correlation and FH showed no correlation with either standardized RCD or RCE.

(a)

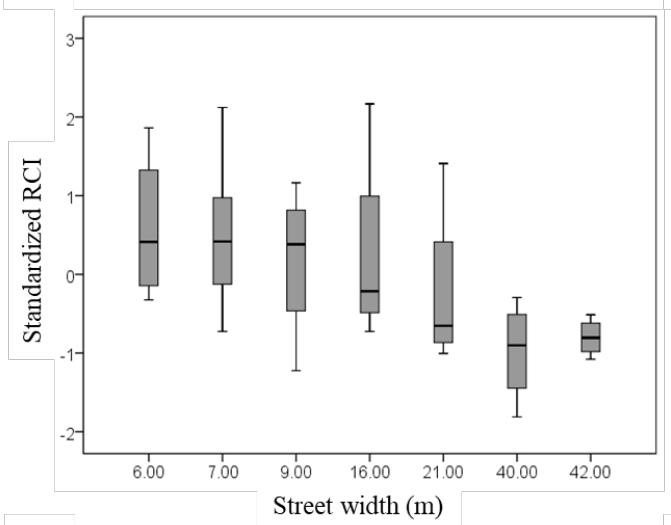

(c)

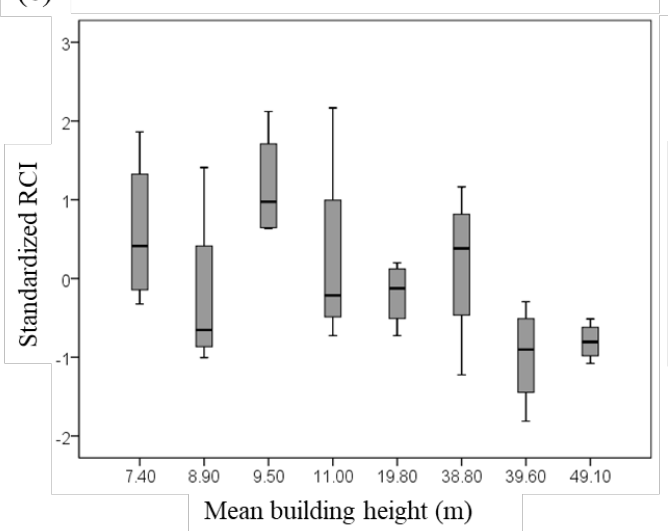

(b)

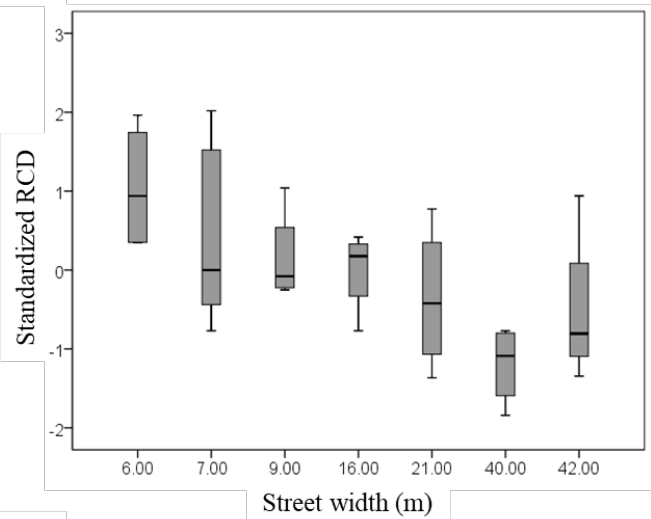

(d)

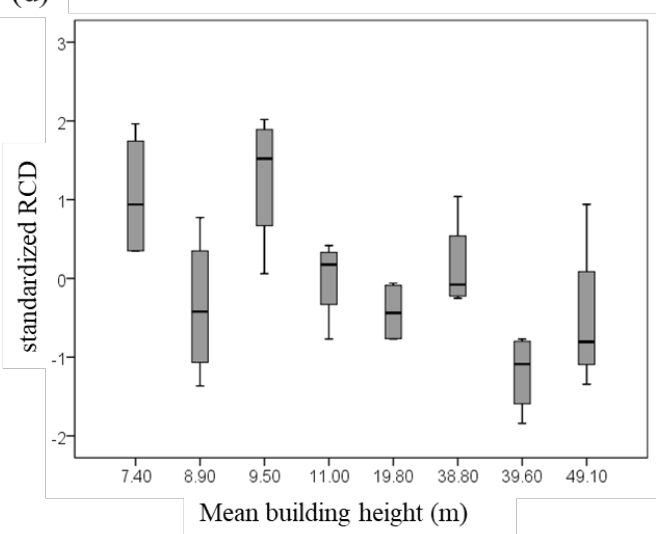

246 Fig. 9. Box plots of RCI with (a) street width and (c) mean building height and RCD with (b) street width and (d) building height at 2 p.m. 
250 During the study, humidity did not change sufficiently to have a significant impact on RCE, 251 except for one day (43.8 \% at 2 p.m., $78 \%$ at 10 p.m.). For three days, the humidity ranged 252 from $53.9-54.3 \%$ at 2 p.m. and $60.2-66.0 \%$ at 10 p.m. However, the wind speed varied from $2531.15-2.03 \mathrm{~m} / \mathrm{s}$ at 2 p.m. and $0.03-1.60 \mathrm{~m} / \mathrm{s}$ at 10 p.m., which did influence the RCE. During 254 daytimes with similar humidity, the Pearson correlation coefficient between wind speed and 255 RCI at 2 p.m. was $0.454(\mathrm{p}<0.05)$ and that between wind speed and RCD was 0.609 $256(\mathrm{p}<0.001)$. There was a positive relationship between wind speed and RCE at 2 p.m., 257 especially for RCD (Fig. 10). At 10 p.m., the Pearson correlation coefficient between wind 258 speed and RCI was $0.151(\mathrm{p}>0.05)$ and that between wind speed and RCD $0.045(\mathrm{p}>0.05)$. 259 Although the correlation at 10 p.m. was smaller than that at 2 p.m., the average RCI and RCD 260 still increased with wind speed. 
(a)

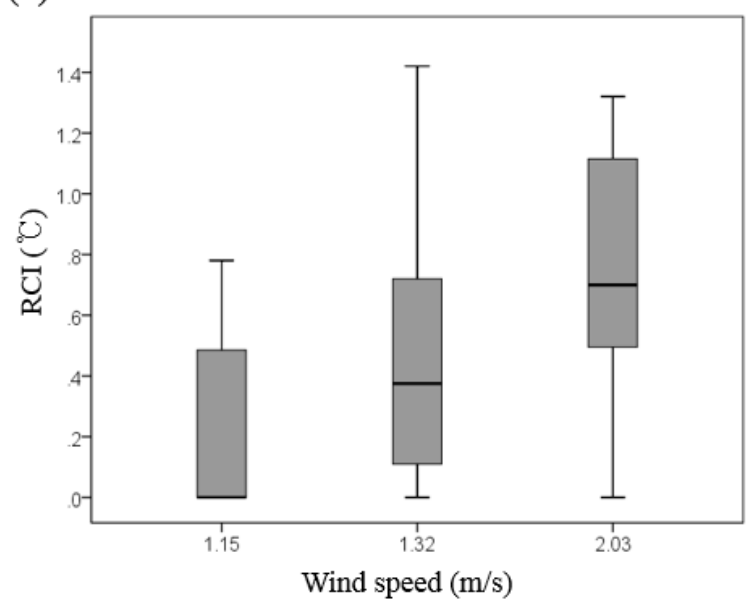

(c)

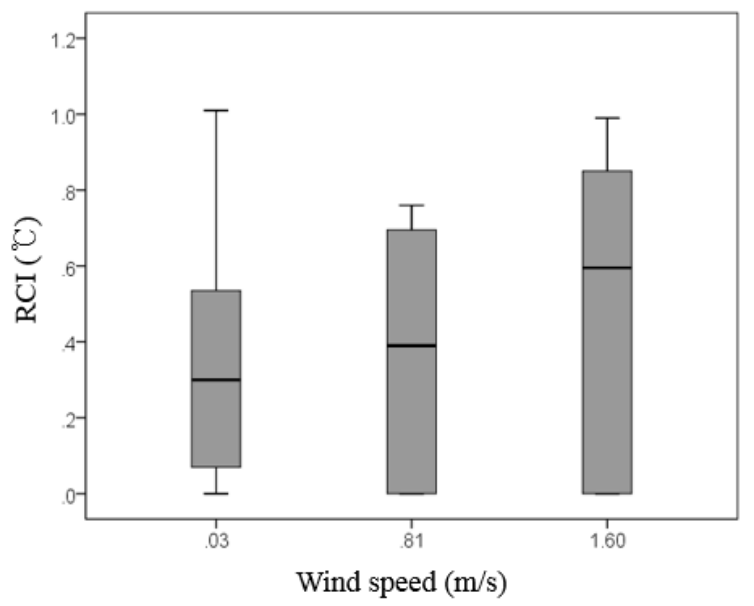

(b)

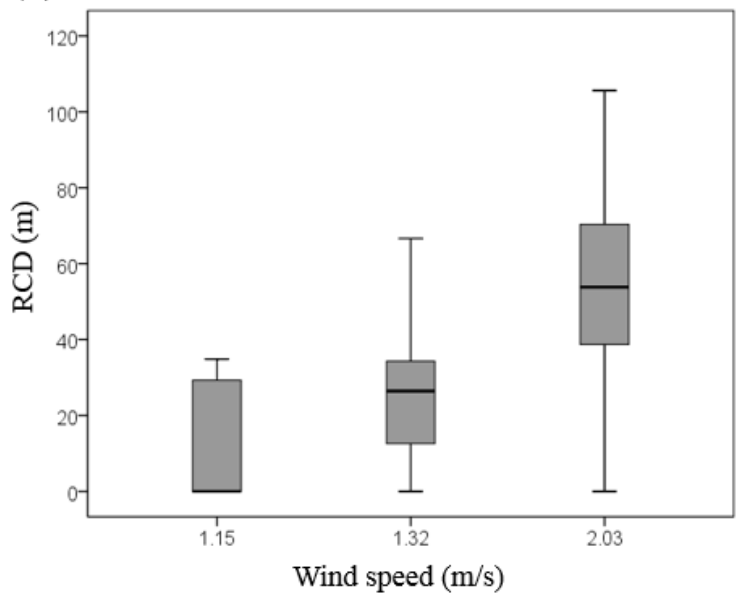

(d)

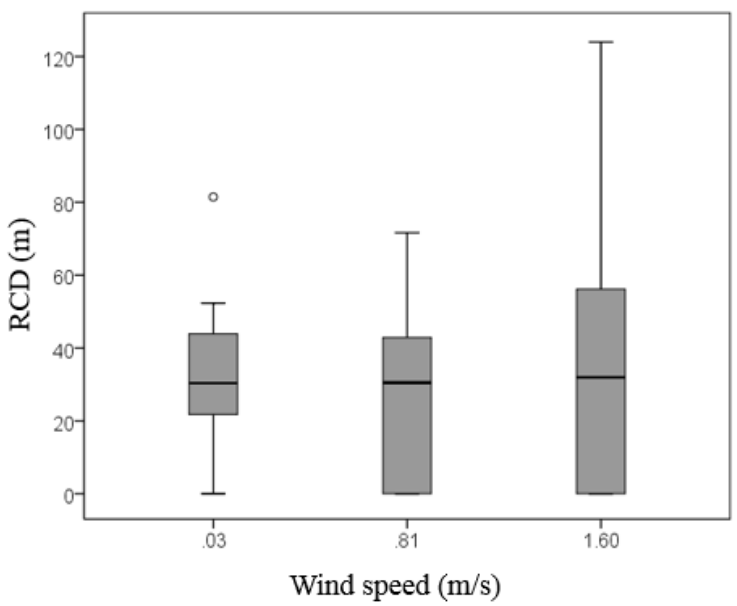

262 Fig. 10. Correlation at 2 p.m. between wind speed and RCI (a) and RCD (b) and at 10 p.m. 263 between wind speed and RCI (c) and RCD (d) for (from left to right) August $24^{\text {th }}$, August $26430^{\text {th }}$, and September $23^{\text {rd }}$.

\section{Discussion}

267 Our results showed a higher RCE for narrow streets with low-rise buildings, confirming our hypothesis regarding the influence of urban form on RCE. Our results also showed that variations in RCE are due to both urban form and date/time. 

measurements. Hathway \& Sharples (2012) reported that the cooling effect of a small urban river was approximately $1{ }^{\circ} \mathrm{C}$ when the ambient temperature was over $20^{\circ} \mathrm{C}$, while Kim et al. (2014) reported a cooling effect of $0.7^{\circ} \mathrm{C}$ at 2 p.m. in South Korea, which was slightly higher than our result. Some studies of larger rivers reported a maximum cooling intensity of $2-5{ }^{\circ} \mathrm{C}$ (Manteghi et al., 2015; Murakawa et al., 1991), a difference most likely due to the different river scale and climate, as large rivers in dry climate with high wind speed have higher a cooling intensity.

Our cooling distances were also very similar to those of Hathway \& Sharples (2012), who points along eight streets. reported a cooling effect for a distance of approximately $30 \mathrm{~m}$ on an open street, while Kim et al. (2014) reported a cooling distance of 60-80 m. Although other studies provided approximate cooling distances based on data from a few measurement stations to represent an overall river cooling distance, our results provide accurate values from close measurement had a higher RCE because this has a strong negative relationship with solar radiation (Hathway \& Sharples, 2012) such that wide streets receive more solar radiation than narrow streets. Furthermore, shade has a greater impact on narrow streets, reducing the amount of solar radiation received (Xuan, Yang, Li, \& Mochida, 2016). Narrow streets also experience greater wind flow interactions while wider streets exhibit isolated wind flows (Blocken,

\subsection{Influence of urban form on RCE}

Our results documented the effects of two major urban forms on RCE. First, narrow streets Carmeliet, \& Stathopoulos, 2007), leading to a higher wind speed in narrower streets and thus 
a larger RCE. Murakawa et al. (1991) argued that the temperature difference between streets and rivers was inversely proportional to the width of the street, in agreement with our results.

Second, building height was negatively correlated with RCE (Fig. 9). Although streets 2 and 5 had the same width, the RCE of street 5 was significantly greater than that of street 2 because of the difference in building height. Taller buildings can receive more radiation on their surfaces and so increase the net radiation toward the street. In addition, taller buildings lead to a larger cross-sectional area of the urban canyon, and wind speeds tend to be lower in large areas (Spirn \& Whiston, 1986). On the other hand, although a previous study argued that high-rise buildings facing the river could block the flow of cool air to their surroundings (Jamei et al., 2016), our results showed an insignificant correlation between FH and RCE. The average building height, rather than the building height facing the river, had a greater effect on RCE. In other words, net radiation and wind speed led to a greater cooling effect in streets with low-rise buildings.

The influence of urban form on RCE was different at 2 p.m. and 10 p.m., suggesting a diurnal effect. The effect of urban form on air temperature was clear during the daytime, but at night there was no significant effect because urban structures stored heat (Middel, Häb, Brazel, Martin, \& Guhathakurta, 2014) that was released and trapped inside the urban canyon (Ryu et al., 2011; Zoulia et al., 2009). Thus trapped heat can negatively influence RCE during the nighttime just as solar radiation does during the daytime.

Although urban microclimates can be significantly affected by urban envelope materials (Alchapar, Correa, \& Cantón, 2014), our study sites were selected to compare only urban forms and therefore consisted of very similar materials. The streets were all asphalt concrete and the buildings were glass, tile, and brick. Although the microclimate could change with 
these materials along the street, it was difficult to accurately distinguish any such variations, so we did not consider envelope materials as a factor.

\subsection{Temporal variation in the RCE}

The RCE varied in both time and space, diurnally and between different days. The RCI and RCD had relatively large daily variations (approximately $50 \%$ of their mean value). The main heat mitigation from the river was due to evaporation, which can be influenced by climate, especially wind speed and humidity (Edinger et al., 1968; Hathway \& Sharples, 2012; Tominaga et al., 2015; Webb \& Zhang, 1997). While humidity was relatively constant in our study, wind speed variability affected the RCE (Fig. 10), suggesting that wind speed increased evaporation by stimulating the movement of water molecules between the river surface and the air, resulting in a higher RCI. Moreover, wind speed allowed these effects to travel a greater distance from the river, increasing the RCD.

Regarding the diurnal difference, our results showed that daytime cooling intensity was higher than nighttime cooling intensity, in agreement with previous studies (Chang et al., 2007; Hathway \& Sharples, 2012; Manteghi et al., 2015). The temperature difference between the water surface and the air is lower at nighttime, resulting in a reduced cooling effect. Moreover, evaporation is known to increase during daytime until late afternoon, when it begins to decrease again (Oke, 1987).

The cooling distance showed a smaller difference between daytime and nighttime, in agreement with the findings of Hathway \& Sharples (2012). Furthermore, the RCE at 10 p.m. showed no correlation with wind speed and urban form. However, we did not evaluate the reasons for diurnal changes in the river cooling distance in detail, and further research is 
necessary to identify which factors influence river cooling distance at night.

\subsection{Future research}

Although our research presented improved measurement methods and revealed the relationship between RCE and urban form, some limitations should be discussed. First, a large number of samples are required to accurately determine urban climate dynamics while a small number of samples results in a limited spatial and temporal scale. Our data focused on a commercial urban form during the summer season, but it cannot be assumed that every urban area will experience the same effect on the RCE as shown in this study. Moreover, building orientation and envelope material are important urban descriptors affecting the urban microclimate, but we did not consider these as variables. In addition, we used four representative days and two representative times of day, but our results cannot necessarily be extrapolated to all days and times of day. 
threshold values might be as important as understanding the effects of different urban forms. For example, we found that building height and RCE were negatively correlated, but an urban planner or designer would need to know the exact building height value that would result in negative effects on the RCE. Therefore, future studies are required to discover such threshold values using simulations or sufficient data collection.

\section{Conclusions}

We analyzed the cooling effect of a small urban river in summer on eight streets in the surrounding area to examine the relationship between the RCE and urban form. We used a mobile survey method with sensitive thermometers composed of T-type thermocouples, radiation shields, and a ventilation fan. We measured the air temperature at $1.5 \mathrm{~m}$ height at $1 \mathrm{~s}$ intervals to obtain a high-resolution horizontal temperature gradient from which we calculated the RCI and RCD. We fitted the measured air temperature gradients with a thirdorder polynomial function and confirmed that this method could also be applied to a micro scale. The results showed a mean cooling intensity of $0.46^{\circ} \mathrm{C}$ and a mean cooling distance of $32.7 \mathrm{~m}$ at 2 p.m., and a mean cooling intensity of $0.37^{\circ} \mathrm{C}$ and a mean cooling distance of 37.2 m at 10 p.m.

We found that the mobile survey method was effective for RCE calculations on a micro scale. Our results also revealed that even a small river could have a cooling distance of over $30 \mathrm{~m}$ on the surrounding urban area, while the intensity of cooling was higher during the daytime than nighttime. Furthermore, the cooling effect on the surrounding areas varied with the urban form, especially street width and mean building height: narrower streets and taller buildings resulted in a larger RCE. We assume that this difference resulted from wind speed 
and radiation flux variations. Furthermore, we found that RCE varied with the measurement time and date because of the wind speed. However, the number of samples used in this study was limited, and the correlation analysis results are insufficient to provide specific guidelines for urban planning. Further studies are required to measure wind speed and radiation for each urban form to determine their specific influence on the river cooling effect. The above limitations can be overcome through a combination of multiple field measurements in various regions and detailed simulation analyses. characteristics. Until now, urban planning did not consider the urban form near rivers with respect to the potential for enhancing the nearby RCE, only considering river size and bank vegetation. Our findings enhance the understanding of RCE by showing that building height and street width correlated to RCE during daytime near a small urban river. However, this result should be carefully applied to urban planning because our limited case study does not necessarily apply to all situations. Further diverse results using the mobile survey methods evaluated in this study are needed to enable urban planners to design more effective urban rivers and mitigate urban warming. 
405

406

407

408

409

410

411

412

413

414

415

416

417

418

419

420

421

422

423

424

425

426

427

428

429

430

431

432

433

434

435

436

437

438

439

440

441

442

443

Abreu-Harbich, L. V., Labaki, L. C., \& Matzarakis, A. (2014). Thermal bioclimate as a factor in urban and architectural planning in tropical climates-The case of Campinas, Brazil. Urban Ecosystems, 17, 489-500. https://doi.org/10.1007/s11252-013-0339-7

Alchapar, N. L., Correa, E. N., \& Cantón, M. A. (2014). Classification of building materials used in the urban envelopes according to their capacity for mitigation of the urban heat island in semiarid zones. Energy and Buildings, 69, 22-32. https://doi.org/10.1016/j.enbuild.2013.10.012

Blocken, B., Carmeliet, J., \& Stathopoulos, T. (2007). CFD evaluation of wind speed conditions in passages between parallel buildings - effect of wall-function roughness modifications for the atmospheric boundary layer flow. Journal of Wind Engineering and Industrial Aerodynamics, 95, 941-962. https://doi.org/10.1016/j.jweia.2007.01.013

Brandsma, T., \& Wolters, D. (2012). Measurement and statistical modeling of the urban heat island of the city of Utrecht (Netherlands). Journal of Applied Meteorology and Climatology, 51(6), 1046-1060. https://doi.org/10.1175/JAMC-D-11-0206.1

Chang, C. R., Li, M. H., \& Chang, S. D. (2007). A preliminary study on the local cool-island intensity of Taipei city parks. Landscape and Urban Planning, 80(4), 386-395. https://doi.org/10.1016/j.landurbplan.2006.09.005

Chen, X. Z., Su, Y. X., Li, D., Huang, G. Q., Chen, W. Q., \& Chen, S. S. (2012). Study on the cooling effects of urban parks on surrounding environments using Landsat TM data: a case study in Guangzhou, southern China. International Journal of Remote Sensing, 33(18), 5889-5914. https://doi.org/10.1080/01431161.2012.676743

Chen, Y. C., Tan, C. H., Wei, C., \& Su, Z. W. (2014). Cooling effect of rivers on metropolitan Taipei using remote sensing. International Journal of Environmental Research and Public Health, 11(2), 1195-1210. https://doi.org/10.3390/ijerph110201195

Coseo, P., \& Larsen, L. (2014). How factors of land use/land cover, building configuration, and adjacent heat sources and sinks explain Urban Heat Islands in Chicago. Landscape and Urban Planning, 125, 117-129. https://doi.org/10.1016/j.landurbplan.2014.02.019

Coutts, A. M., Tapper, N. J., Beringer, J., Loughnan, M., \& Demuzere, M. (2012). Watering our cities: The capacity for Water Sensitive Urban Design to support urban cooling and improve human thermal comfort in the Australian context. Progress in Physical Geography, 37(1), 2-28. https://doi.org/10.1177/0309133312461032

Du, H., Song, X., Jiang, H., Kan, Z., Wang, Z., \& Cai, Y. (2016). Research on the cooling island effects of water body: A case study of Shanghai, China. Ecological Indicators, 67, 31-38. https://doi.org/10.1016/j.ecolind.2016.02.040

Edinger, J., Dutterweiler, D., \& Geyer, J. (1968). The response of water temperatures to meteorological conditions. Water Resources Research, 4(5), 1137-1143. https://doi.org/10.1029/WR004i005p01137

Feyisa, G. L., Dons, K., \& Meilby, H. (2014). Efficiency of parks in mitigating urban heat 
island effect: An example from Addis Ababa. Landscape and Urban Planning, 123(MARCH), 87-95. https://doi.org/10.1016/j.landurbplan.2013.12.008

Hathway, E. A., \& Sharples, S. (2012). The interaction of rivers and urban form in mitigating the Urban Heat Island effect : A UK case study. Building and Environment, 58, 14-22. https://doi.org/10.1016/j.buildenv.2012.06.013

He, J., \& Hoyano, A. (2010). Measurement and evaluation of the summer microclimate in the semi-enclosed space under a membrane structure. Building and Environment, 45(1), 230-242. https://doi.org/10.1016/j.buildenv.2009.06.006

Honjo, T., \& Takakura, T. (1990). Simulation of Thermal Effects of Urban reen Areas on Their Surrounding Areas. Energy and Buildings, 16, 443-446. https://doi.org/10.1016/0378-7788(90)90019-F

Imhoff, M. L., Zhang, P., Wolfe, R. E., \& Bounoua, L. (2010). Remote sensing of the urban heat island effect across biomes in the continental USA. Remote Sensing of Environment, 114(3), 504-513. https://doi.org/10.1016/j.rse.2009.10.008

Jaganmohan, M., Knapp, S., Buchmann, C. M., \& Schwarz, N. (2016). The Bigger, the Better? The Influence of Urban Green Space Design on Cooling Effects for Residential Areas. Journal of Environment Quality, 45(1), 134. https://doi.org/10.2134/jeq2015.01.0062

Jamei, E., Rajagopalan, P., Seyedmahmoudian, M., \& Jamei, Y. (2016). Review on the impact of urban geometry and pedestrian level greening on outdoor thermal comfort. Renewable and Sustainable Energy Reviews, 54, 1002-1017. https://doi.org/10.1016/j.rser.2015.10.104

Katayama, T., Hayashi, T., Shiotsuki, Y., \& Kitayama, H. (1990). Cooling Effects of a River and Sea Breeze on the Thermal Environment in a Built-up Area. Energy and Buildings, 16(3-4), 973-978. https://doi.org/10.1016/0378-7788(91)90092-H

Kim, D., Cha, J., \& Jung, E. (2014). A Study on the Impact of Urban River Refurbishment to the Thermal Environment of Surrounding Residential Area. Journal of Environmental Protection, 5(5), 454-465. https://doi.org/10.4236/jep.2014.55048

Kim, Y. H., Ryoo, S. B., Baik, J. J., Park, I. S., Koo, H. J., \& Nam, J. C. (2008). Does the restoration of an inner-city stream in Seoul affect local thermal environment? Theoretical and Applied Climatology, 92(3-4), 239-248. https://doi.org/10.1007/s00704-007-0319-z

Lee, S. (2011). Further Development of the Vegetated Urban Canopy Model Including a Grass-Covered Surface Parametrization and Photosynthesis Effects. Boundary-Layer Meteorology, 140, 315-342. https://doi.org/10.1007/s10546-011-9603-7

Lin, W., Yu, T., Chang, X., Wu, W., \& Zhang, Y. (2015). Calculating cooling extents of green parks using remote sensing: Method and test. Landscape and Urban Planning, 134, 66-75. https://doi.org/10.1016/j.landurbplan.2014.10.012

Manteghi, G., Lamit, H. bin, \& Ossen, D. R. (2015). Influence of Street Orientation and Distance To Water Body on Microclimate Temperature Distribution In Tropical Coastal City of Malacca. International Journal of Applied Environmental Sciences, 10(2), 749- 
Middel, A., Häb, K., Brazel, A. J., Martin, C. A., \& Guhathakurta, S. (2014). Impact of urban form and design on mid-afternoon microclimate in Phoenix Local Climate Zones. Landscape and Urban Planning, 122, 16-28. https://doi.org/10.1016/j.landurbplan.2013.11.004

Mills, G. (1997). An urban canopy-layer climate model. Theoretical and Applied Climatology, 57(3-4), 229-244. https://doi.org/10.1007/BF00863615

Mochida, A., \& Lun, I. Y. F. (2008). Prediction of wind environment and thermal comfort at pedestrian level in urban area. Journal of Wind Engineering and Industrial Aerodynamics, 96(10-11), 1498-1527. https://doi.org/10.1016/j.jweia.2008.02.033

Murakawa, S., Sekine, T., Narita, K., \& Nishina, D. (1991). Study of the effects of a river on the thermal environment in an urban area. Energy and Buildings, 16(3-4), 993-1001. https://doi.org/10.1016/0378-7788(91)90094-J

Nunez, M., \& Oke, T. R. (1977). The Energy Balance of an Urban Canyon. Journal of Applied Meteorology. https://doi.org/10.1175/15200450(1977)016<0011:TEBOAU $>2.0 . \mathrm{CO} ; 2$

O’Loughlin, J., Witmer, F. D. W., Linke, A. M., Laing, A., Gettelman, A., \& Dudhia, J. (2012). Climate variability and conflict risk in East Africa, 1990--2009. Proceedings of the National Academy of Sciences, 109(45), 18344-18349.

Oke, T. R. (1987). Boundary Layer Climates (2d ed.). London. UK:Routledge: Taylor \& Francis Group.

Oke, T. R. (2004). Initial guidance to obtain representative meteorological observations at urban sites. World Meteorological Organization, (81), 51. https://doi.org/Reporte

Rajkovich, N. B., \& Larsen, L. (2016). A Bicycle-Based Field Measurement System for the Study of Thermal Exposure in Cuyahoga County, Ohio, USA. International Journal of Environmental Research and Public Health, 13(2), 159. https://doi.org/10.3390/ijerph13020159

Rizwan, A. M., Dennis, L. Y. C., \& Liu, C. (2008). A review on the generation, determination and mitigation of Urban Heat Island. Journal of Environmental Sciences, 20, 120-128. https://doi.org/10.1016/S1001-0742(08)60019-4

Saaroni, H., \& Ziv, B. (2003). The impact of a small lake on heat stress in a Mediterranean urban park: the case of Tel Aviv, Israel. International Journal of Biometeorology, 47(3), 156-165. https://doi.org/10.1007/s00484-003-0161-7

Spirn, A. W., \& Whiston, A. (1986). Air quality at street-level: Strategies for urban design. Boston Redevelopment Authority. Cambridge.

Stewart, I. D. (2011). Redefining the Urban Heat Island. Vancouver. Retrieved from https://circle.ubc.ca/handle/2429/38069

Stewart, I. D., \& Oke, T. R. (2012). Local climate zones for urban temperature studies. Bulletin of the American Meteorological Society, 93(12), 1879-1900. https://doi.org/10.1175/BAMS-D-11-00019.1 
Sugawara, H., Shimizu, S., Takahashi, H., Hagiwara, S., Narita, K., Mikami, T., \& Hirano, T. (2015). Thermal influence of a large green space on a hot urban environment. Journal of Environment Quality, O(0), 0. https://doi.org/10.2134/jeq2015.01.0049

Sun, R., Chen, A., Chen, L., \& Lü, Y. (2012). Cooling effects of wetlands in an urban region: The case of Beijing. Ecological Indicators, 20, 57-64. https://doi.org/10.1016/j.ecolind.2012.02.006

Tominaga, Y., Sato, Y., \& Sadohara, S. (2015). CFD simulations of the effect of evaporative cooling from water bodies in a micro-scale urban environment: Validation and application studies. Sustainable Cities and Society. https://doi.org/10.1016/j.scs.2015.03.011

Vidrih, B., \& Medved, S. (2013). Multiparametric model of urban park cooling island. Urban Forestry and Urban Greening, 12(2), 220-229. https://doi.org/10.1016/j.ufug.2013.01.002

Webb, B. W., \& Zhang, Y. (1997). Spatial and seasonal variability in the components of the river heat budget. Hydrological Processes. https://doi.org/10.1002/(SICI)10991085(199701)11:1<79::AID-HYP404>3.3.CO;2-E

Xuan, Y., Yang, G., Li, Q., \& Mochida, A. (2016). Outdoor thermal environment for different urban forms under summer conditions, 281-296. https://doi.org/10.1007/s12273-016-0274-7 
$545 \quad$ List of tables

546 Table 1 Average air temperature based on the measuring date from AWS $\left({ }^{\circ} \mathrm{C}\right)$.

547 Table 2 Urban form descriptors of the 8 streets, including street width (SW), mean building

548 height $(\mathrm{MH})$, and average height of buildings fronting the river (FH).

549 Table 3 Pearson correlation between the urban form descriptors and RCE.

550

551 
552 Table 1 Average air temperature based on the measuring date from AWS $\left({ }^{\circ} \mathrm{C}\right)$.

\begin{tabular}{|l|l|l|}
\hline \multicolumn{1}{|r|}{ Time } & 2 p.m. & 10 p.m. \\
\hline $8 / 24$ & & \\
\hline $8 / 30$ & 22.4 & 26.8 \\
\hline $9 / 09$ & 27.3 & 17.8 \\
\hline $9 / 23$ & 26.1 & 21.4 \\
\hline Average & 27.7 & 20.4 \\
\hline
\end{tabular}

553

554 
555 Table 2 Urban form descriptors of the 8 streets, including street width (SW), mean building

556 height $(\mathrm{MH})$, and average height of buildings fronting the river $(\mathrm{FH})$.

\begin{tabular}{|l|l|l|l|l|l|l|l|l|}
\hline & 1 & 2 & 3 & 4 & 5 & 6 & 7 & 8 \\
\hline Sariable (m) & & & & & & & & \\
\hline MH (m) & 42 & 7 & 9 & 40 & 7 & 16 & 21 & 6 \\
\hline FH (m) & 49.1 & 19.8 & 38.8 & 39.6 & 9.5 & 11.0 & 8.9 & 7.4 \\
\hline Building orientation & N-S & N-S & N-S & N-S & N-S & N-S & N-S & N-S \\
\hline
\end{tabular}

557

558

559 
560 Table 3 Pearson correlation between the urban form descriptors and RCE.

\begin{tabular}{|c|c|c|c|}
\hline & & Standardized RCI & Standardized RCD \\
\hline & SW & $-0.554 * *$ & $-0.567 * *$ \\
\hline 2 p.m. & $\mathrm{MH}$ & $-0.466 * *$ & $-0.458 * *$ \\
\hline & $\mathrm{FH}$ & -0.266 & -0.346 \\
\hline & SW & -0.023 & -0.182 \\
\hline & $\mathrm{MH}$ & -0.001 & -0.115 \\
\hline & $\mathrm{FH}$ & -0.023 & 0.061 \\
\hline$* * \mathrm{p}<$ & & & \\
\hline
\end{tabular}

561

562 
564 Fig. 3. Conceptual diagram of the urban river cooling effect (RCE) (image reproduced from 565 Honjo \& Takakura, 1990).

566 Fig. 4. Flow chart showing the analysis procedures used in this study.

567 Fig. 3. Monitoring sites on the Cheonggye River (blue line). Red lines indicate the tracks of 568 eight mobile street surveys; the blue star marks a fixed-location automatic weather station.

569 Fig. 4. Schematic depiction of an urban canyon (image reproduced from Nunez \& Oke, 570 1997).

571 Fig. 5. Measurement devices used in this study: (a) moving survey thermometers and (b) 572 fixed-location weather station.

573 Fig. 6. Schematic diagram of river cooling intensity (RCI) and river cooling distance (RCD).

574 Fig. 7. Horizontal air temperature gradients at 2 p.m. on August $24^{\text {th }}, 2016$. (a) Explicit 575 function: air temperature initially increases with distance from the river and streets show 576 positive RCE values. (b) Implicit function: air temperature initially decreases with distance 577 from the river and streets show zero.

578 Fig. 8. RCI and RCD for each street calculated at (a) 2 p.m. and (b) 10 p.m. Dotted lines 579 show the range of values.

580 Fig. 9. Box plots of RCI with (a) street width and (c) mean building height and RCD with (b) 581 street width and (d) building height at 2 p.m.

582 Fig. 10. Correlation at 2 p.m. between wind speed and RCI (a) and RCD (b) and at 10 p.m. 583 between wind speed and RCI (c) and RCD (d) for (from left to right) August $24^{\text {th }}$, August $58430^{\text {th }}$, and September $23^{\text {rd }}$.

List of Appendices

Appendix 1. Supplementary data

Measured air temperature (grey dots) and fitted third-order polynomial graphs (black lines) of 8 streets and 4 days. $\mathrm{X}$-axis denotes air temperature $\left({ }^{\circ} \mathrm{C}\right)$ and $\mathrm{y}$-axis denotes the distance from the river. 


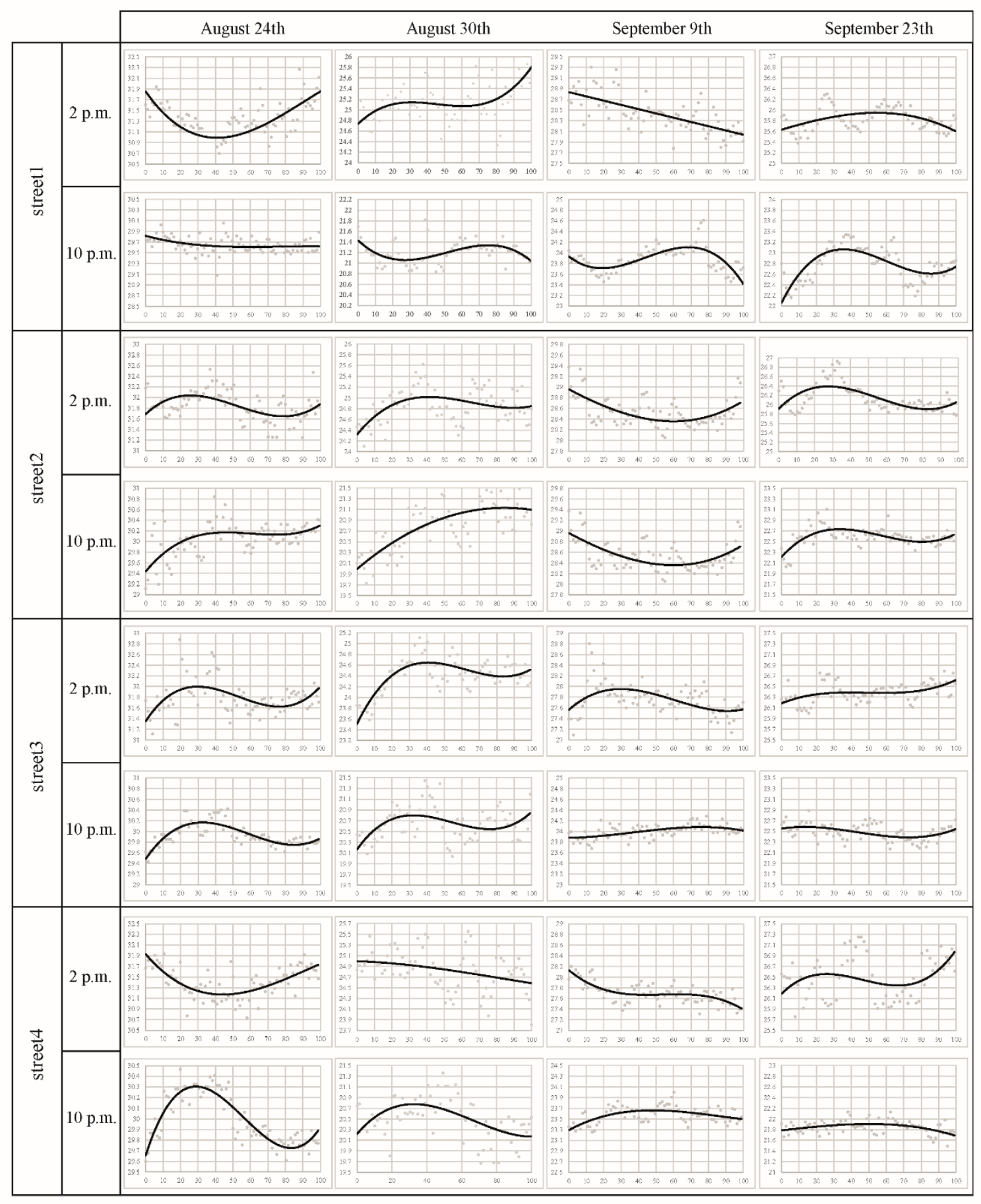




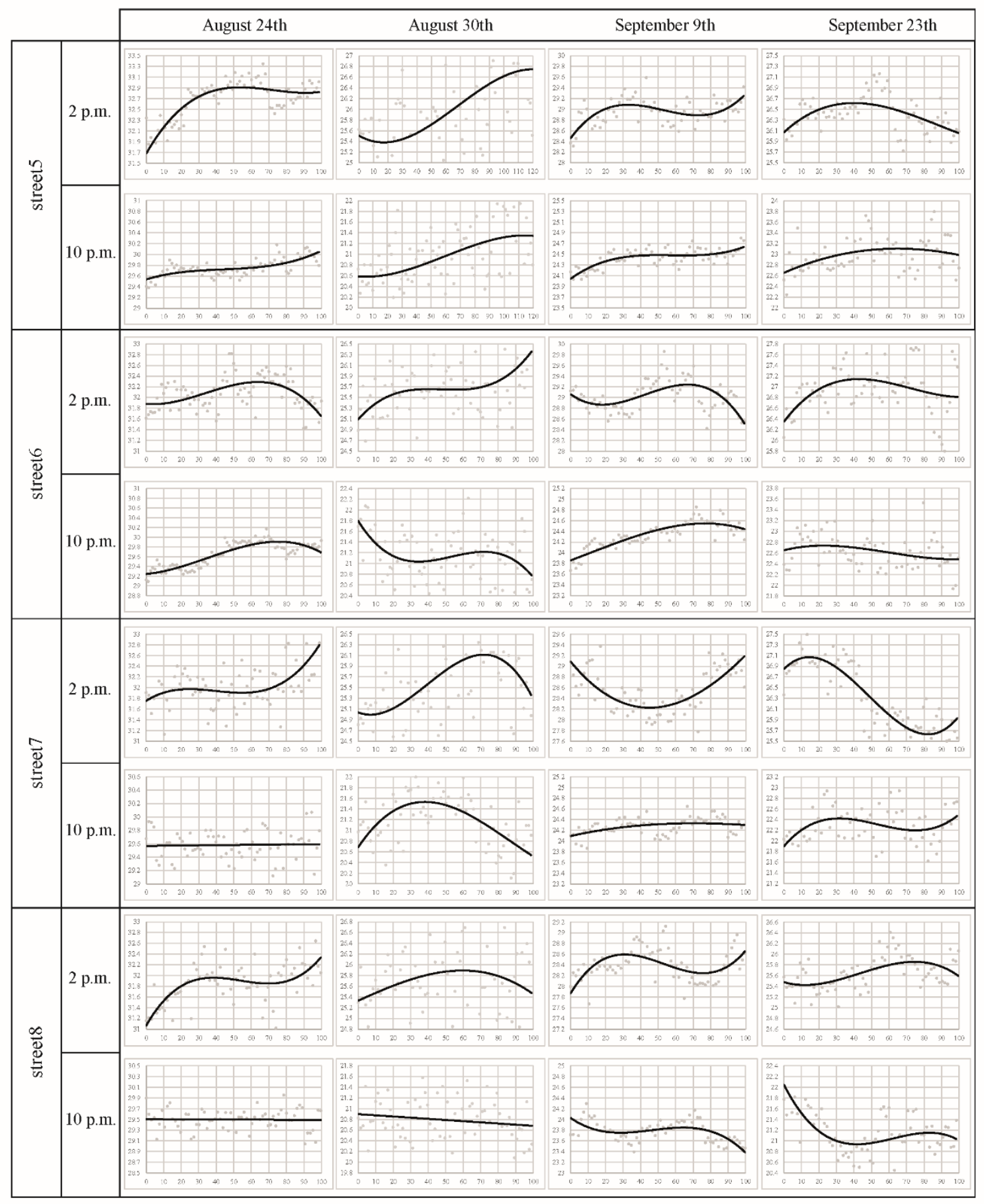

